\title{
INTERDITO E SILÊNCIO: ANÁLISE DE ALGUNS ENUNCIADOS
}

Fabio Elias Verdiani Tfouni

Fabio Elias Verdiani

Tfouni

Doutor em Letras (Unesp/ Araraquara), professor adjunto II do Departamento de Letras de Itabaiana da Universidade Federal de Sergipe (UFS).

\begin{abstract}
RESUMO: O presente trabalho - situado no campo da Análise do Discurso de Pêcheux (AD), numa interface com a psicanálise trata o interdito e o silêncio como constitutivos e fundadores do discurso. A lógica subjacente é a lógica lacaniana segundo a qual o excluído ou a contradição funda o possível. Para tal tarefa usamos as quatro modalidades da lógica alética aristotélica e tratamos o quadrado lógico. Propomos e construímos um quadrado do dito e da enunciação. As análises de alguns enunciados indicam a presença do impossível na linguagem, e atestam a importância, bem como a pertinência, de um tratamento modal da linguagem.
\end{abstract}

Palavras-chave: Discurso, interdito, silêncio.

ABSTRACT: Interdiction and silence: analysis of some utterances. Within the field of Discourse Analysis (Pêcheux) and psychoanalysis, this work states interdiction and silence as constituents and founders of the discourse. In short, we claim that what makes it possible to say anything is that it is not possible to say it all, so something must remain unsaid. The logic principle here is that the contradiction, the excluded founds the possible. For such task we use the logic square. We also propose and build a square of the saying or of the utterances. The analysis made here points toward the existence of the impossible in language, and also indicates how important a modal approach of language can be.

Keywords: Discourse, interdiction, silence. 


\section{INTRODUÇÃO}

O presente trabalho dá continuidade à nossa pesquisa sobre o interdito e o silêncio (TFOUNI, 2006, 2008). Nos trabalhos anteriores abordamos o interdito como fundador do discurso e propusemos que ele possui uma ligação forte com o silêncio tal como tratado por Orlandi (1995). Retomamos a tese (ORLANDI, 1995) de que o silêncio possui estatuto de fundador e de constitutivo e propomos que ambos, o interdito e o silêncio, são fundadores e constitutivos do discurso e da linguagem. Além disso, um dos objetivos centrais era verificar quais são as condições para a existência da linguagem. Por isso, esses trabalhos podem ser vistos como uma investigação sobre a origem da linguagem, não em uma perspectiva histórica, mas sim lógica. Só se pode tratar a origem da linguagem através da lógica. Assim, perguntamos: "por que existe linguagem ao invés de nada?".

O interdito é fundador e constitutivo do discurso porque se fosse possível dizer tudo, não diríamos nada: se existisse uma enunciação ou um enunciado completo que dissesse tudo o que há para dizer, após essa enunciação não haveria mais nada a dizer. Assim, a existência de uma enunciação completa seria a morte da linguagem. Portanto, para que o campo do dizível permaneça aberto é preciso que não se diga tudo e que a linguagem seja carregada também de um não dizer, de um interdito ao dizer, do equívoco, da falta. Assim, o interdito é um impedimento estrutural e estruturante ao dizer completo, impedindo que se diga tudo, e, por isso mesmo, permitindo que se diga algo. O dizer é sempre faltante, é sempre meio-dito, dito no meio, dito pela metade: inter-dito.

Vale dizer que os três conceitos — interdito, silêncio e não-dito — não são a mesma coisa, embora estejam sempre juntos. O interdito seria como um operador que incide sobre o silêncio real, sobre a plenitude de sentidos do silêncio permitindo que parte dessa matéria significante se transforme em linguagem com a condição de que uma porção desses sentidos permaneça sempre em silêncio (cf. TFOUNI, 2008).

Ao abordar o silêncio como constitutivo do dizer, Orlandi (1995) afirma que o silêncio é o espaço diferencial da linguagem, é o espaço que permite à linguagem significar. Para nós, ele é este espaço, mas o que cria tanto o silêncio quanto o discurso é uma interdição. Essa interdição é ela mesma uma operação linguística: é a entrada da linguagem que cria tanto o discurso quanto o silêncio. Conforme Orlandi, haveria uma flutuação entre silêncio e dizer. Para nós, é uma interdição que funda essa flutuação.

Orlandi afirma que "A hipótese de que partimos é que o silêncio é a condição da produção de sentido. Assim, ele aparece como o espaço 'diferencial' da significação: lugar que permite à linguagem significar” (ORLANDI, 1995, p.70). Aqui, Orlandi já aponta algo fundamental para a tese do interdito: o fato de que 
para que a linguagem diga algo, para que se instaurem sentidos linguisticamente, é preciso considerar que a linguagem necessita de um lugar "outro”. Esse lugar “outro” ou "diferente” é o silêncio, que, por sua vez, é indistinto. Para que a linguagem signifique, ela precisa atualizar sentidos desse silêncio e, ao mesmo tempo, recusar alguns sentidos. É assim que lemos a definição do silêncio como espaço diferencial da linguagem. Portanto, a afirmação de Orlandi de que o silêncio seria o "lugar que permite à linguagem significar" aponta para a necessidade estrutural de um excluído, para que a linguagem possa, enfim, significar. Isto quer dizer que a existência do não dito e, portanto, de um impossível de dizer, é estruturalmente necessária ao dizer, ao discurso e à enunciação.

Antes da enunciação, todos os dizeres são possíveis. O que é dito seria uma “escolha” contingente do enunciatário. Segue-se que, uma vez dito X, esse X passa de contingente para impossível, pois não é possível que o sujeito não tenha dito X. O impossível é entendido aqui, ao mesmo tempo como aquilo que não pode ser simbolizado e aquilo que não pode ser de outro modo; como afirma Pêcheux: “'há real', isto é, pontos de impossível, determinando aquilo que não pode não ser 'assim'. (O real é o impossível... que seja de outro modo)” (PÊCHEUX, 1990, p. 29).

Antes da enunciação, o campo dos sentidos abre-se como um real da significação, posto que é exterior à linguagem, sendo, nestes termos, impossível. Após a enunciação, o silêncio se configura como o que deixou de ser dito, mas que poderia ter sido dito; em outras palavras, o silêncio também é contingente. Para Milner, o impossível e o contingente constituem os dois lados do real. Tanto o que é dito como o que é silenciado possuem um real, devendo ser modalizados pelo impossível e pelo contingente. A respeito do lado do dito, podemos lembrar Milner (1987), para quem o real da língua é o impossível. Essa dinâmica entre o que é dito e o que é silenciado é tratada por nós por meio da metáfora do lance de dados (TFOUNI, 2008) presente em Milner (1996), que não aparece aqui por necessidade de concisão. Esta metáfora permite conceber o dito e o silêncio através das quatro modalidades aléticas da lógica aristotélica.

Em Orlandi (1995), o silêncio é a possibilidade de flutuação dos sentidos. Em nossa proposta, esta flutuação só seria possível a partir de um operador: a interdição ou o interdito. Esta operação seria o corte do interdito, que impede o dizer completo e que permite, por isso mesmo, a existência de algum dizer.

O objetivo do presente trabalho é continuar essa reflexão já feita sobre o interdito e o silêncio em suas relações com as modalidades lógicas aléticas aristotélicas, a saber, o possível e o impossível, o necessário e o contingente, utilizando para isso o quadrado lógico aristotélico (quadrado das oposições), sobrepondo a ele o quadrado das modalidades. 
Vale destacar que embora o quadrado tomado seja o aristotélico ${ }^{1}$, a lógica subjacente à nossa reflexão não é a aristotélica e sim a lógica lacaniana, na qual a contradição, o excluído, funda o possível. Há, portanto, uma relação direta com o interdito e o silêncio como fundadores do campo do dizer: o silêncio é o excluído desse campo e, justamente como excluído, torna possível a linguagem. A tese do silêncio como fundador seria, nesse caso, uma tese na qual a contradição, o excluído, funda o possível, no caso, a possibilidade de se dizer.

Este trabalho trata, então, da contradição como fundadora do possível, inspirado pelos princípios da lógica paraconsistente, que não condenam a contradição já de saída. Sobre isso, afirma Da Costa:

“A lógica paraconsistente não condena a contradição, de início, como necessariamente falsa. Mas, em geral, se uma contradição é verdadeira ou falsa isto não depende tão somente de fatores lógicos. Uma contradição que ocorre, por exemplo, na física, para ser julgada, avaliada, tem que ser vista como que mergulhada no domínio da física e não apenas como fato lógico.” (DA COSTA, 1986, p.32)

É no sentido apontado por Da Costa (1986) que tratamos o interdito e o silêncio, pois o princípio que norteará este trabalho é o princípio lacaniano segundo o qual "o excluído funda a regra". Aliás, vale dizer, ao menos de passagem, que a entrevista de Da Costa (1989) versa sobre essa lógica lacaniana. Por isso não se trata apenas da lógica estrita, mas da lógica no campo de investigação em questão, que aqui é a Análise do Discurso (AD) numa interface com a psicanálise. Ao tratar sobre a lógica da sexuação, Lacan afirma que a exceção funda a regra:

“À esquerda, a linha inferior, $\forall \mathrm{x} \Phi \mathrm{x}$, indica que é pela função fálica que o homem encontra seu limite na existência de um x pelo qual a função $\Phi$ x é negada, $\exists \mathrm{x} \neg \Phi \mathrm{x}^{2}$. Aí está o que chamamos função do pai — de onde procede pela negação a proposição $\neg \Phi_{\mathrm{x}}$, o que funda o exercício do que supre, pela castração, a relação sexual — no que esta não é de nenhum modo inscritível. O todo repousa, portanto, aqui, na exceção colocada, como termo, sobre aquilo que, esse $\Phi_{x}$, o nega integralmente." (LACAN 1985, p. 107, grifo nosso.)

\footnotetext{
${ }^{1}$ Embora seja comum chamar esse quadrado de aristotélico, a rigor, ele não foi construído por Aristóteles, mas por lógicos posteriores.

${ }^{2}$ O símbolo de negação usado aqui é diferente do de Lacan, por motivos tipográficos. A negação usada aqui é da lógica e aparece fartamente na literatura, como em Carnielli \& Pizzi (2001).
} 
Nessa citação fica clara a lógica lacaniana, pois ele afirma que "o todo repousa [...] na exceção”. De modo análogo, fazemos a hipótese de que, no universo discursivo, a existência de algo (um "pelo menos um”) fora do discursivo possa ser o que permite conceber o universo discursivo. É assim que lemos o seguinte trecho de Leite:

"O tema do interdito se refere aqui à imposição, consequente da própria estrutura da linguagem, do fato de não se poder abarcar todos os significantes ao mesmo tempo. A relação específica que vige entre linguagem-inconsciente-castração tem como implicação que não se pode dispor do conjunto dos significantes.” (LEITE, 1994, p. 92)

\section{0 quadrado lógico}

Apresentamos a seguir (fig.1) o quadrado lógico (ou quadrado das oposições) e as relações entre os cantos:

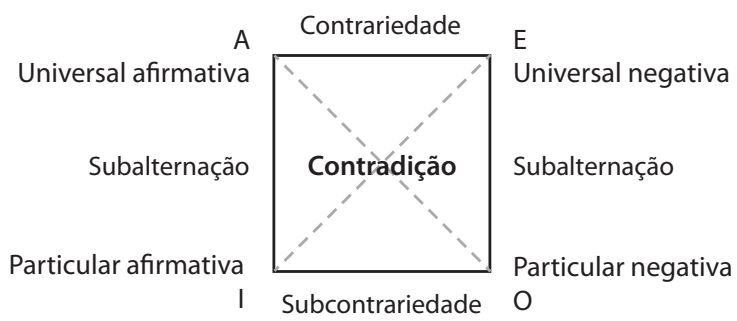

(Figura 1)

Em nossa pesquisa encontramos, entre diferentes maneiras de conceber o quadrado lógico modal, uma com o contingente no canto-O (ver Darrault, 1976; Greimas, 1976; Da Costa, 1986) e outra com o possível não no canto-O (ver Béziau, 2003).

No quadrado são colocadas proposições categóricas. Segundo Copi (1978), as proposições categóricas têm uma qualidade e uma quantidade. O autor prossegue afirmando que "A qualidade de uma proposição é afirmativa ou negativa [...] segundo a inclusão de classe for afirmada ou negada pela proposição" (COPI, 1978, p. 143). Então, as proposições universais afirmativas e particulares afirmativas são afirmativas em qualidade. As do outro lado, as negativas, são negativas em qualidade.

Sobre a quantidade, Copi afirma: "A quantidade de uma proposição é universal ou particular segundo a proposição se refira a todos os membros ou só a alguns dos membros da classe designada pelo seu termo sujeito" (COPI, 1978, 
p.143). Assim, as proposições dos cantos A e E são universais e as dos cantos I e O são particulares.

O quadrado das oposições não é apenas uma figura geométrica, mas é uma figura na qual os cantos possuem certas relações lógicas, de modo que as relações entre as proposições, que são relações de oposição, são determinadas pelas posições que estas ocupam no quadrado. Sobre isso, afirma Copi:

"As proposições categóricas de forma típica que têm os mesmos termos sujeito e predicado podem diferir mutuamente na qualidade ou na quantidade ou em ambas as coisas. Os lógicos de outrora deram a essa espécie de diferença o nome técnico de 'oposição' e certas relações importantes dos valores de verdade foram correlacionadas com várias espécies de oposição.” (COPI, 1978, p.146)

\subsection{PRIMEIRA VERSÃO DO QUADRADO MODAL}

Quanto ao primeiro quadrado, também conhecido como 'quadrado semiótico' (DARRAULT, 1976; GREIMAS, 1976; DA COSTA, 1986), o que precisamos destacar aqui é que ele apresenta as quatro modalidades aléticas: o possível, o impossível, o necessário e o contingente. Eis o quadrado (fig. 2):

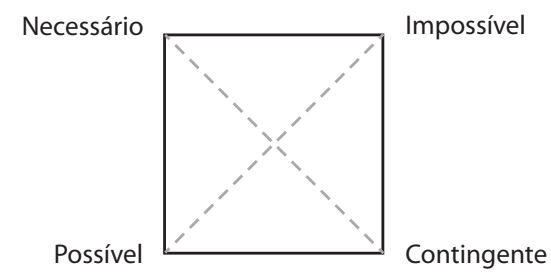

(Figura 2)

Percebemos que este quadrado apresenta no lado negativo (canto-E e canto-O) as duas modalidades que para Milner (1996) constituem o real (o contingente e o impossível). Este seria um motivo para pesquisarmos as relações entre esse quadrado, as modalidades e as questões do campo da linguagem que estamos investigando.

Neste quadrado vemos que o contingente ocupa a posição de subalterno ao impossível, sendo ele (o contingente) a contradição do necessário. Ora, é justamente nesse eixo de contradição que se encontra o par de modalidades que está em jogo na lógica lacaniana da sexuação. A lógica da sexuação é baseada numa aporia lógica na qual a contradição não é negada, mas ao contrário, comparece como fundadora. Vale dizer que diversos autores apontam que o uso feito por 
Lacan da lógica aristotélica é proposital, intencional, não se trata de um engano ou erro (ver Leite, 1994 e Loparic, 1991).

Para o que está sendo tratado neste trabalho, a principal diferença de Lacan com a lógica tradicional seria justamente o princípio lacaniano no qual nos baseamos, que como já dissemos, afirma que "a exceção funda a regra”, constituindo-se numa contradição. Segundo Copi (1978), a contradição é uma relação na qual uma proposição é a negação da outra, tanto na qualidade quanto na quantidade, não podendo ser ambas verdadeiras nem falsas. Afirma Copi: “Duas proposições são contraditórias se uma delas for a negação da outra, isto é, se não puderem ser ambas verdadeiras e não puderem ser ambas falsas" (COPI, 1978 p.146). Então, os usos lacanianos não estão de acordo com os princípios da lógica nem com as relações tradicionais do quadrado porque violam quase todas as relações e escritas lógicas tradicionais. Ainda de um ponto de vista tradicional, outros problemas surgem quando colocamos a modalidade do canto-O no canto-A, como por exemplo, problema na relação de subalternação entre o canto-A e o canto-I.

Da Costa (1989) constrói alguns quadrados em sua leitura dos “diagramas das fórmulas quânticas da sexuação de Lacan”. Um deles é o que está a seguir (fig. 3):

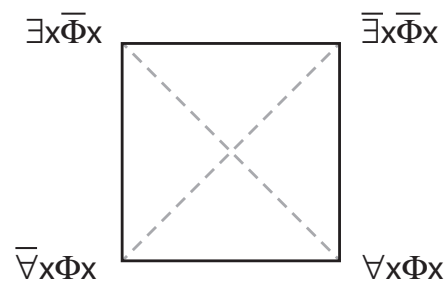

(Figura 3. Fonte: Da Costa, 1989, p.33)

No quadrado de Da Costa (1989) que está acima, podemos ver a particular negativa ( $\exists \mathrm{x} \neg \Phi_{\mathrm{x}}$ ) ocupando o lugar da universal afirmativa ( $\forall \mathrm{x} \Phi_{\mathrm{x}}$ ) o que denota o papel fundador da particular negativa, que no quadrado modal acima seria o contingente. Desse modo, o contingente ocupa a posição fundadora, sendo ele, nesse caso, o excluído que funda a regra. Sobre a exceção que funda a regra, Magno afirma: "A única coisa que extrapola o todo desta lei é a exceção. Exceção, aliás, que funda a regra” (MAGNO, 1986, p.13).

Então, a lógica subjacente às formulas da sexuação é uma lógica na qual a exceção funda a regra. O elemento excluído (a exceção, a particular negativa, como vimos), justamente por essa exclusão, funda o campo do possível. Esse excluído é o pai primevo de Freud (1995a), figura em relação à qual se dá a possibilidade de estruturação da sexuação humana. O pai primevo é elemento 
fora do simbólico, é o pai real, dono de todas as mulheres. Com inveja do pai primevo os filhos matam o pai e o consomem num repasto canibalesco. O resultado desse processo é que o pai real agora se torna o pai simbólico, se torna o grande Outro, de modo que esse pai real, essa exceção que não é submetida à lei, torna-se o elemento que dá origem à lei. Então, o pai primevo como elemento excluído, contingente e contraditório, como o um que não é submetido à função fálica $\left(\exists \mathrm{x} \neg \Phi_{\mathrm{x}}\right)$, é o pivô em torno do qual se funda a sexualidade masculina como submetida à lei, de onde temos que o excluído é o fundador e se constitui como estruturante do todo $\left(\forall \mathrm{x} \Phi_{\mathrm{X}}\right)$. Mais ao final, veremos como isso se relaciona com o dito, o não-dito e o interdito. O que acontece então, é que o contingente antecede o possível. Leite comenta a anterioridade do excluído sobre o possível na lógica da sexuação:

“A modalidade do necessário vai se constituir, portanto, deste pelo menos um que, exterior ao domínio da lei universal, funda o campo do possível por ela delimitado. É a particular negativa $(\exists \mathrm{x} \neg \Phi \mathrm{x})^{3}$ que define o necessário, diferentemente de Aristóteles para quem o necessário era da ordem da universalidade da lei. Esta definirá em Lacan a modalidade do possível ( $\forall$ x Фx)." (LEITE, 1994, p.91)

Outro ponto chave da abordagem lacaniana (ver LACAN, 1998) que se aproxima de nossa reflexão é a metáfora paterna (fig. 4). Na metáfora paterna, o significante "nome do pai" substitui o significante "desejo da mãe”, de modo que o preço da ascensão à linguagem é o de não se poder significar por completo o "desejo da mãe”, que é sempre um enigma para o sujeito que se apresenta como "O que sou eu no desejo do outro?". Assim, o sujeito busca sua verdade, sua essência, mas o último termo da metáfora paterna deixa claro que não há esse significado (do sujeito), o que há é castração, a verdade do sujeito consiste no buraco deixado pela castração. O preço da ascensão à linguagem é a impossibilidade de o sujeito significar tudo, ou dizer tudo. No entanto é justamente isso que torna possível que se diga alguma coisa. Então, nem tudo daquele silêncio originário (ORLANDI, 1995) pode ser transformado em fala: é necessário que um corte intervenha, impedindo que se diga tudo e permitindo que se diga alguma coisa. A fórmula abaixo, de Lacan, formaliza a metáfora paterna (fig. 4):

\footnotetext{
${ }^{3}$ Por uma questão de concisão não esclarecemos ao leitor de maneira mais detalhada como Lacan concebe essas fórmulas da sexuação. Como na citação de Lacan, usamos um operador de negação diferente do de Leite. Ambos usam um traço sobre o fi $(\Phi)$. Vale explicitar ao leitor que esse símbolo $(\Phi)$ na fórmula representa a função fálica.
} 
$\frac{\text { Nome-do-Pai }}{\text { Desejo da Mãe }} \cdot \frac{\text { Desejo da Mãe }}{\text { Significado para o sujeito }} \rightarrow$ Nome-do-Pai $\left(\frac{A}{\text { Falo }}\right)$

(Figura 4. Extraída de LACAN, 1998, p.563)

Reforçando nosso tratamento da questão do pai como operador da interdição e da fundação de uma ordem discursiva podemos citar os seguintes trechos de Leite (1994):

"Neste sentido, a introdução da Lei no plano do significado, naquilo em que este sempre já se dá como significante, equivale à introdução da Lei da Diferença, vale dizer, Lei do Pai, como instauradora da ordem do desejo, constituindo seu correlato, a castração, como o significado imposto a qualquer sujeito falante." (LEITE, 1994, p.35)

Para a autora, a partir do momento em que praticamos uma linguística sensível ao discurso psicanalítico, temos que situar a função paterna: "Afirmar que o inconsciente é estruturado como uma linguagem implica introduzir a função paterna e consequentemente a castração no campo dos estudos da linguagem" (LEITE, 1994, p.37).

A lógica da sexuação e a metáfora paterna estão fortemente ligadas, na medida em que o que está em jogo em ambas é a proibição do incesto de modo bastante próximo ao formulado por Lévi-Strauss (2003) (ver Dor, 1991; TFOUNI, 1998).

Então, talvez possamos tratar a metáfora de modo semelhante ao feito com as fórmulas da sexuação, pois o significante do desejo da mãe é o significante que deve ser excluído, que deve ficar de fora para que haja a entrada do sujeito na linguagem, de modo que é excluindo (silenciando?) o significante do desejo da mãe que há a entrada da linguagem no sujeito. Para haver linguagem é preciso haver um "fora”, um excluído que pode muito bem se afigurar como um contraditório, como o excluído que fornece as condições para o possível.

O pai primevo é esse contingente, é esse excluído fora da lei que, justamente por isso, funciona como fundador da lei. É por isso que em psicanálise o pai primevo corresponde a Deus: aquele que passa a ser mais poderoso morto do que em vida (ver Dor, 1991 e Freud, 1995a). Deus é aquele que é exterior ao nosso mundo e, enquanto exterior, funda o nosso mundo. Ele é o criador. Nesse sentido ele é como o pai primevo: é o todo-poderoso (não é submetido à função fálica, à castração) exterior ao universo que cria o universo. 


\subsection{SEGUNDA VERSÃO DO QUADRADO MODAL}

A diferença deste quadrado (GEERTS \& MELIS, 1976) para o quadrado anterior é que, enquanto naquele o canto-O é modalizado pelo contingente, este traz o possível não modalizando o canto-O. Este é um tratamento diferente do ponto de vista lógico. Alguns lógicos têm proposto (BÉZIAU, 2003) que o contingente não pode ocupar o canto-O, pois nessa posição ele violaria ${ }^{4}$ a relação de subalternação ao impossível (canto-E), já que sendo o contingente aquilo que pode ser ou pode não ser seria inadequado colocá-lo no canto-O em relação de subalternação ao impossível. Desse modo, temos o quadrado a seguir (fig. 5):

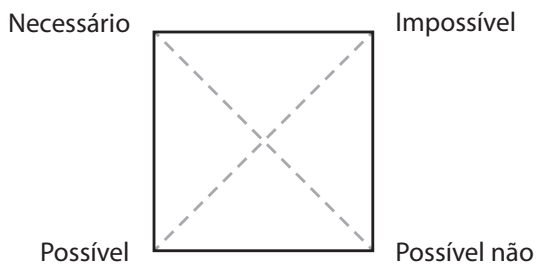

(Figura 5)

Nesse caso a contradição da universal (necessário) afirmativa é o possível não, de modo que é este, e não contingente que ocupa a posição de fundador, e que corresponde ao $\exists \mathrm{x} \neg \Phi_{\mathrm{x}}$ no canto-A do quadrado de Costa, acima.

\section{0 quadrado do dito ou da enunciação}

Aqui tomamos os quadrados (tradicional e modal) para propor um quadrado do dito ou da enunciação que se constrói a partir da proposição da universal afirmativa tudo se diz. Sua contrária, a universal negativa, seria então nada se diz. A subalterna da universal afirmativa seria a particular afirmativa algo se diz e a subalterna da universal negativa, a particular negativa algo não se diz. O quadrado do dito e da enunciação fica então assim (fig. 6):

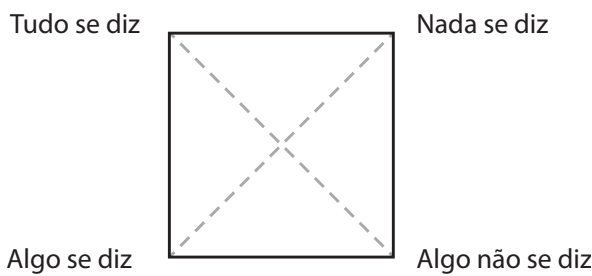

(Figura 6)

\footnotetext{
${ }^{4}$ Para alguns autores, o contingente estaria mais bem posicionado em outra figura, o hexágono de Blanché, tal como apontado em Béziau (2003). Em trabalho posterior faremos o tratamento deste hexágono.
} 
Para a Análise do Discurso, o tratamento do não dito é fundamental na medida em que compreender os processos de produção de um discurso seria compreender por que se diz algo e por que outros dizeres possíveis são silenciados, inclusive porque para a AD o silêncio é constitutivo do dito e do dizer como apontamos aqui. Essa concepção de linguagem é cara a Pêcheux (1993, 2002), que afirma a importância da seleção de certos enunciados que serão ditos e de outros que serão excluídos. Ou seja, para nós, como para Pêcheux (ver Pêcheux \& Fuchs, 1993) e Orlandi (1995), o não-dito tem anterioridade sobre o dito: o não-dito precede e determina o dito. Para tratar o não-dito como anterior e constitutivo do dito, aplicamos o princípio lacaniano de que "o excluído (a contradição) funda a regra”. No caso, é necessário silenciar alguns sentidos para que outros possam se instaurar. Isso indica que aquilo que é preciso deixar de fora precede e constitui o dizer. Então, na figura 6, a particular negativa (canto-O) tem estatuto de fundadora, pois ela é a contradição, o excluído.

Vale apontar ainda que, em trabalhos posteriores teremos como objetivo colocar o interdito e o silêncio no quadrado buscando indicar que posição cada um ocupa. Este trabalho será feito em outro momento, pois sua execução pode requerer a inclusão de outros tipos de modalidades como as modalidades deônticas.

\subsection{O QUADRADO QUANTIFICADO}

É possível continuar tratando o quadrado do dito ou da enunciação colocando nos vértices as proposições quantificadas para “Tudo se diz”, quando temos a fórmula $\forall \mathrm{x}$ Dx; “Nada se diz”, ( $\neg$ x Dx); “Algo se diz” ( $\exists \mathrm{x}$ Dx); e “Algo não se diz” ( $\exists x \neg D x)$. Com as fórmulas quantificadas, o quadrado fica assim (fig. 7):

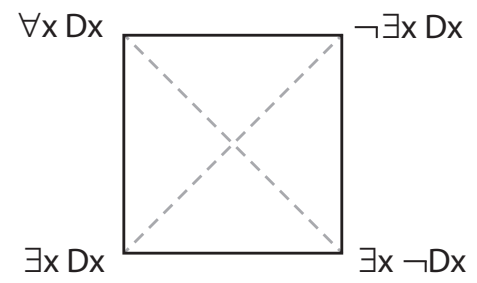

(Figura 7)

A colocação da particular negativa como fundadora se aplica também ao quadrado quantificado. Isto se justifica já que a existência de um não-dito é fundamento para a abertura do campo do dizer. É justamente por não ser possível que se diga tudo, que se diz alguma coisa. Para nós, parece haver ao menos uma relação de analogia entre nosso tratamento do dito, do interdito, do silêncio e da linguagem com a lógica lacaniana da sexuação na qual a exceção é que funda a regra. Podemos perceber a particular negativa (canto-O) como fundadora nos 
dois quadrados (o quadrado do dito ou da enunciação e o quadrado quantificado) fundando o possível.

\section{Análise de enunciados}

Como já dissemos, a entrada da linguagem no sujeito por meio da metáfora paterna, que tem o nome do pai como significante operador da castração, implica que não se pode dizer o mais importante, o fundamental: com a entrada do sujeito na linguagem, o sujeito não pode ter acesso ao significado de sua existência, no sentido de que o desejo da mãe fica interditado. Há então a falta de um significante que é, ao mesmo tempo, falta do sujeito e falta da linguagem, que deste momento em diante será sempre falha, faltante, constituída pelo equívoco. Essa falta se materializa na enunciação cotidiana, como aponta o trabalho de AuthierRevuz (1994), que traz enunciados nos quais a autora indica a existência de um impossível, de uma falta. Essa falta enquanto constitutiva e fundadora acaba por motivar as estratégias do sujeito no processo de enunciação, estratégias que visam a uma negociação do sujeito com esse impossível, seja para denunciá-lo, para desviar-se dele, etc. Diz Authier-Revuz:

“[...] surge no próprio princípio da nomeação a dimensão de uma perda, de uma falha em nomear — que para o sujeito faltante é particularmente falha para se nomear, falha para dizer a verdade que não se diz toda porque as palavras faltam." (AUTHIERREVUZ, 1994, p.253)

A autora afirma que existem algumas tentativas de resposta radical a essa falta como o sonho do dizer sem falta, completo, inequívoco, ou a recusa a dizer, o desejo de permanecer em silêncio. Provavelmente, o mais comum é a negociação do sujeito com a falta do dizer (um meio caminho entre o dizer tudo [impossível] e o dizer nada):

“Aquém da radicalidade destas 'respostas' à ferida da falta do dizer — sonho do dizer sem falta, o silêncio do não-dizer, a escritura como adesão à ferida do dizer

- abre-se o campo da negociação cotidiana dos enunciadores em seu dizer — suas falas, seus escritos mais diversos — com esta falta que o afeta [...].” (AUTHIERREVUZ, 1994, p.254-255)

O "sonho de dizer tudo" apontado aqui por Authier-Revuz, é apenas um sonho, pois a língua é constitutivamente falha. O sujeito pode desejar que o dizer seja completo, para que ele mesmo seja completo, apresentando em seu dizer uma negação imaginária da completude. Por exemplo, em: 


\section{"Diga tudo em uma palavra."}

Poderíamos dizer, sobre este enunciado, que o sujeito tem uma necessidade (necessário) de imaginar que o interlocutor é um sujeito completo, necessidade constitutiva do sujeito que faz com que este sonhe com o enunciado completo (no sentido de um enunciado que diga tudo) ou, que sonhe com uma língua completa sem equívocos ou falhas.

Tomemos então alguns enunciados (a, b, c, d) presentes em Authier-Revuz (1994):

a) "Tratou-se até aqui essencialmente [...] do que poder-se-ia chamar rapidamente de gramática." (Exemplo retirado de AUTHIER-REVUZ, 1994, p.257)

A falta em nomear, no exemplo acima, seria resultado da pressa (dizer rapidamente) do sujeito que não se dá ou não tem tempo suficiente para buscar o termo adequado. Note-se então que existe aí um “erro”, ou no mínimo uma imperfeição, vista pelo sujeito como contingente, pois poderia ser ultrapassada se o sujeito não fosse rápido. O impossível de dizer aparece aí imaginariamente como um lapso contingente do sujeito, não como uma falta estrutural da língua.

b) "Este silêncio, digamos, grosso modo, sobre o Édipo como forma estruturante do desejo do sujeito." (Exemplo retirado de AUTHIER-REVUZ, 1994, p.257)

Neste exemplo notamos que o sujeito negocia com a falta sem corrigi-la, mas não deixa de apontar que ali existe uma falta, presente sob a forma do dizer "grosso modo". Isto indica que o sujeito chega a aceitar um dizer imperfeito, mas que o faz indicando esse dizer imperfeito, indicando que não é exatamente aquilo que ele quer dizer.

c) "Toda língua cujos locutores se dispersam está submetida ao fenômeno da fragmentação dialetal. Ela se reproduz, por assim dizer, por cissiparidade" (Exemplo retirado de AUTHIER-REVUZ, 1994, p.267)

Aqui, o uso do "por assim dizer" denota um retorno do enunciado sobre si mesmo indicando que o dito foi um modo de dizer, mas que o dito poderia ser outro, o que significa que o dito é contingente e que não é necessário (já que se poderia dizer de outro modo). A cissiparidade é uma figura, uma metáfora que ilustra a separação dos falantes em regiões (ou grupos) diferentes, o que ocasiona uma evolução "diferenciada” para cada grupo. Assim o dialeto de uma língua surge, entre outros motivos, de uma separação análoga à cissiparidade. 
d) [...] "era obrigado a falar primeiro dos aspectos códigos, quer dizer, coletivos transindividuais, que asseguram a comunicação no sentido mais simples do termo." (Exemplo retirado de AUTHIER-REVUZ, 1994, p.263)

Este trecho indica que o sujeito vê uma necessidade de "falar primeiro dos aspectos códigos", ou seja: que para ele a enunciação tinha que iniciar por ali, ou que não podia não começar por ali. Mesmo que esta seja uma impressão imaginária, ela pode ser uma indicação de que existe o necessário e o impossível na língua. O "quer dizer" entra aqui como uma estratégia de reparação que visa consertar o mau-dizer, a falta do enunciado que é falta constitutiva da linguagem. Essa operação recupera para o sujeito ao mesmo tempo a sua falta e a falta da linguagem, sendo esses os objetivos apontados por Authier-Revuz (1994) como das modalizações autonímicas.

De modo geral, nos parece que esses exemplos podem ser explicados pelos esquecimentos descritos por Pêcheux. O sujeito imerso nos esquecimentos $\mathrm{N}^{\circ} 1$ e No2 (Ver Pêcheux \& Fuchs, 1993) imagina que ele pode dizer exatamente o que ele pensa, e não percebe que isso é uma ilusão. Ou seja: o sujeito imagina que ele é a origem do enunciado e que ele é capaz de dizer exatamente o que pensa de modo transparente e inequívoco. Ele acredita em um casamento perfeito (necessário) entre a palavra escolhida e o que ele quer dizer, então a falta do dizer, que é falta do próprio sujeito, é vista como contingente, como um engano contornável.

Essa falta constitutiva é cara à $\mathrm{AD}$ e, um dos pontos onde ela aparece em Pêcheux é no texto "Só há causa daquilo que falha ou o inverno político francês: início de uma retificação” (PÊCHEUX, 1995). Ora, a máxima no título do texto é própria de uma abordagem lacaniana do sujeito e do desejo. Ela indica que a falta não é apenas ausência (é presença da ausência), mas causa de desejo, sendo por isso mesmo estruturante da linguagem. A linguagem necessita de um ponto cego, de um impossível para que possa existir, e não é só isso: esse ponto cego é causa mesmo do sujeito e da linguagem, já que o sujeito é sujeito da/na linguagem. Pode-se dizer que na própria obra de Pêcheux há indicações dessa falha necessária à existência da linguagem (como o texto referido antes). Então, existe a necessidade de um excluído que funda a regra, esse excluído é o ponto cego, a falta constitutiva, que para nós é também falta fundadora. É havendo falta que existe linguagem, de onde se aponta também que o gesto inaugurador da falta, aqui chamado de interdito, é fundador também. Então, percebemos que a lógica segundo a qual "o excluído funda a regra" possui lugar nos estudos da linguagem. Vale apontar também que essa abordagem se constitui numa aporia lógica, o que significa dizer que numa leitura tradicional o fundamento lógico da existência da linguagem é uma aporia lógica. 
Para os estudos da linguagem o tratamento dos enunciados aqui exemplificados é fundamental ao indicar que as teses apontadas neste trabalho vão além da teorização permitindo a abordagem de dados linguísticos.

Em trabalhos posteriores procuraremos abordar o interdito, o silêncio, o dito e o não-dito em exemplos mais próximos da psicanálise e da clínica psicanalítica. Particularmente, nos interessam exemplos do próprio Freud, como o esquecimento pelo próprio Freud do nome do pintor Signoreli relatado por ele na "Psicopatologia da vida cotidiana" (FREUD, 1995b). Esses exemplos talvez possam tratados por uma abordagem modal.

Outra questão dentro da psicanálise que nos interessa é a associação livre (LAPLANCHE \& PONTALIS, 1995), tipo especial de fala/discurso que se dá em análise e que pode aproximar os campos da linguagem e da psicanálise numa abordagem modal.

\section{CONSIDERAÇÕES FINAIS}

Acreditamos que o que foi exposto é suficiente para corroborar nossa tese de que o interdito é fundador do discurso (e para discuti-la a partir do quadrado lógico) e, principalmente, para ir além. Essa tese é a de que é preciso que não se diga algo para que seja possível alguma enunciação. A interdição de uma parte do domínio do dizer e do discurso é fundadora e constitutiva, já que para dizer $\mathrm{X}$ deixamos de dizer $\mathrm{Y}$.

O todo do silêncio não pode se atualizar como todo, então é preciso que restem enunciados não ditos ou silenciados para que exista discurso. Se fosse possível dizer tudo, se existisse um enunciado completo, que dissesse tudo, esse enunciado seria a morte da linguagem.

Apresentamos duas versões do quadrado lógico e discutimos como pensar, a partir delas, a lógica lacaniana de que a exceção funda a regra. Na lógica da sexuação, o pai primevo, enquanto único que não é submetido à função fálica, funda a possibilidade de estruturação da sexuação humana. É justamente porque esse um (esse pai) excluído não é submetido à lei, à função fálica, que todos os homens o são. Em relação ao dizer, afirmamos, de modo análogo, que também é a existência de um excluído que funda o possível. Esse excluído ocupa a posição do canto-O no quadrado do dito, independentemente se consideramos que esse canto é modalizado pelo contingente ou pelo possível não.

Com base nisso propomos a criação do quadrado do dito ou da enunciação, que forneceu a possibilidade de pensarmos de outra maneira uma consideração já cara à $\mathrm{AD}$ : a de que o silenciado, que o não-dito enquanto excluído, tem anterioridade sobre o dito e, que o não-dito é constitutivo e fundador do dito. 
Propomos e construímos o "quadrado do dito e da enunciação", em mais de uma versão. Neles temos o tudo se diz ou $\forall \mathrm{x}$ Dx (necessário), o algo se diz ou $\exists$ x Dx (possível), o nada se diz ou $\neg \exists x$ Dx (impossível), e o algo não se diz ou $\exists x \neg D x$ (que corresponde ao canto- $\mathrm{O}$, independente de o preenchimento desse canto ser o contingente ou ser o possível não).

As análises feitas sustentam o exposto aqui, deixando clara a presença de um impossível na linguagem, um impossível fundador com o qual o sujeito tem de lidar para enunciar, e ele o faz tentando apagar a falta que é constitutiva a ele (sujeito) e ao seu dizer. As análises também permitem ver em um corpus as vantagens de um tratamento modal da linguagem.

O que foi dito aqui coloca o interdito e o silêncio como fundadores do discurso, afirmando que o não-dito precede o dito no sentido de que é havendo não-ditos — é havendo silêncio — que pode existir algum dizer.

O estudo da fala na associação livre através de uma abordagem modal pode ser um caminho de estudo futuro que permitirá um aprofundamento da interface entre a análise do discurso e a psicanálise, enriquecendo ambas as áreas. Este estudo pode levar à compreensão da questão fala/enunciação/discurso em relação às condições lógicas de possibilidades de dizer e significar (inclusive em situação de análise). E como o sujeito é sujeito da/na linguagem, essas condições lógicas podem ser também as condições do sujeito para falar de (e significar a) si mesmo.

Recebido em 7/10/2010. Aprovado em 24/1/2011.

\section{REFERÊNCIĀS}

BEZIAU, J-Y. (2003) New light on the square of oppositions and it's nameless corner, in Logical Investigations, v. 10. Rússia: Nauka Publishers. A versão citada está disponível em: <http://www.unine.ch/unilog/ jyb/sep.pdf.> Acesso em 28/9/2009.

CARNIELLI, W.A. \& PIZZI, C. (2001) Modalità e multimodalità. Milão: FrancoAngeli.

COPI, I.M. (1978) Introdução à lógica. São Paulo: Mestre Jou.

DA COSTA, N. (1989) Entrevista, Isso - dispensa freudiana, n.1. Belo Horizonte.

DARRAULT, I. (1976) Présentation, Langages, n.43. p.3-9.

DOR, J. (1991) O pai e sua função em psicanálise. Rio de Janeiro: Jorge Zahar. 
FREUD, S. (1995a) Obras psicológicas completas: Trad. Órizon Carneiro Muniz. 2 ed. Rio de Janeiro: Imago.

[1913] “Totem e tabu”, v.XIII, p.21-163.

[1901] "Sobre a psicopatologia da vida cotidiana”, v.VI, p.11-247.

GEERTS, W. \& MELIS, L. (1976) Remarques sur le traitement des modalités en linguistique. Langages, n.43, p.108-115.

GREIMAS, A. J. (1976) Pour une théorie des modalités. Langages, n.43, p.47-63.

LACAN, J. (1985) O Seminário, Livro 20. Mais, ainda. Rio de Janeiro: Jorge Zahar.

(1998) “De uma questão preliminar a todo tratamento possível da psicose", in Escritos. Rio de Janeiro: Jorge Zahar.

LAPLANCHE, J. \& PONTALIS, J-B. (1995) Vocabulário da psicanálise. São Paulo: Martins Fontes, p.38-40.

LEITE, N. (1994) Psicanálise e análise do discurso — O acontecimento na estrutura. Rio de Janeiro: Campo Matêmico.

LEVI-STRAUSS, C. (2003) As estruturas elementares do Parentesco. Trad. Mariano Ferreira. Petrópolis: Vozes.

LOPARIC, A. (1991) "Lês négations et les univers du discurs", in Lacan avec les Philosophes. Paris: Albin Michel.

MAGNO, M.D. (1986) “Não me sonhem nem me outrem”, in Poética e psicanálise. Rio de Janeiro: Aoutra.

MILNER, J-C.L. (1987) O amor da língua. Trad. Ângela Cristina Jesuino. Porto Alegre: Artes Médicas.

(1996) A obra clara. Trad. Procópio Abreu. Rio de Janeiro: Jorge Zahar.

ORLANDI, E.P. (1995) As formas do silêncio — no movimento dos sentidos. 3 ed. Campinas: Ed. Unicamp.

PÊCHEUX, M. (1995) “Só há causa daquilo que falha ou o inverno político francês: início de uma retificação”, in Semântica e discurso — uma crítica à afirmação do óbvio. Campinas: Editora da Unicamp.

. (2002) O discurso: estrutura ou acontecimento? Trad. Eni Puccinelli Orlandi. Campinas: Pontes.

\& FUCHS, C. (1993) "A propósito da análise automática do discurso: atualização e perspectivas”, in GADET, F \& HAK, T. (Orgs.) Por uma análise automática do discurso — uma introdução à obra de Michel Pêcheux. 2 ed. Trad. Péricles Cunha. Campinas: Ed Unicamp, p.163-252.

TFOUNI, F.E.V. (1998) "O interdito como fundador do discurso". Dissertação de Mestrado em Linguística. Instituto de Estudos da Linguagem, Universidade Estadual de Campinas, Campinas.

(2006) O interdito como fundador do discurso. Letras \& Letras, Edufu, Uberlândia, v. 22, n.1, p.127-137, jan./jun. . (2008) O interdito e o silêncio: duas abordagens do impossível na linguagem. Linguagem em (Dis)curso, Unisul, Tubarão, v.8, n.2, maio-ago. 


\section{OBRAS CONSULTADAS}

SAUSSURE, F. (1994) Curso de linguística geral. 19 ed. Trad. Antônio Chelini, José Paulo Paes e Izidoro Blikstein. São Paulo: Cultrix.

TFOUNI, L.V. (1986) Adultos não alfabetizados: 0 avesso do avesso. Tese (Doutorado em Linguística) — Instituto de Estudos da Linguagem, Universidade Estadual de Campinas, Campinas.

Fabio Elias Verdiani Tfouni

fabiotfouni@hotmail.com 